\title{
Is geographic diversification sufficient to limit contract grower risk?
}

\author{
M Geyser'1, A Louw² \& L Botha ${ }^{3}$
}

\begin{abstract}
Lending and financial institutions have looked for a variety of ways to expand their portfolios into agriculture, but because of the risks associated with lending to farmers who lack traditional forms of collateral, they face price and yield risks, causing these inroads to be limited. Market-based instruments are readily available for price risk. Organised exchanges offering the most basic of these instruments, futures and options, have operated for a long time, providing transparency to the market and low-cost risk transfer tools for those able to access them. While the use of price risk management instruments is an incomplete solution, it has sufficient merits on its own and will make the overall burden of risk more bearable. The use of these instruments and multiperil crop insurance products is expensive and does not provide full protection for financial lending institutions to limit their credit risk exposure. This article determines whether geographic diversification would be sufficient as a risk management tool for lending institutions to limit their credit risk.
\end{abstract}

Keywords: Geographic diversification; contract grower; risk; lending; rainfall; yield

\section{Introduction}

South African agriculture is in the process of undergoing transformation, and agribusinesses need to be proactive when coping with the new challenges and expectations. It needs to reposition itself in many ways and develop new strategies and products in changing supply value chains. The risk environment is changing and, especially in developing agriculture, a more innovative approach is required to deal with the new challenges, pressures and risks. The process of Black Economic Empowerment (BEE) also requires a more proactive approach, as many stakeholders in the agriculture value chain are impacted by it in various ways.

\footnotetext{
${ }^{1}$ Dr Mariette Geyser holds the Nedbank Chair of Commodity Finance and Risk in the Department of Agricultural Economics, Extension and Rural Development, University of Pretoria, Pretoria, 0002; E-mail: Mariette.Geyser@up.ac.za

${ }^{2}$ Prof Andre Louw holds the ABSA Agribusiness Chair in the Department of Agricultural Economics, Extension and Rural Development, University of Pretoria, Pretoria, 0002; E-mail: andre.louw@up.ac.za

${ }^{3}$ Grainvest, P.O. Box 25752, Monument Park, 0105; E-mail: louisb@gvf.co.za
} 
New products are required for BEE projects. No reliance can be placed on tangible security other than multi-peril risk insurance, but pre-emergence risk needs to be mitigated by, for example, diversifying into different geographic areas as well as minimising pre-plant costs on projects. The purpose of this article is to identify the risks and risk mitigating solutions for the agricultural projects in which financial institutions are involved in geographically dispersed areas (Lichtenburg and Heidelberg). The risks involved are those that occur during different phases of sowing and establishment, growth and flowering, yield formation and harvest. The purpose is to minimise the value at risk for the various financial and lending institutions at acceptable costs. This can impact on the design of current and future solutions.

The specific objectives of the article are to determine the probability of all risks related to hail, drought, flooding, heat, frost, and the probability of other risks that may occur, including those that occur simultaneously in all planted areas. Another objective is to focus on the uninsured parts of the risk and to make some recommendations on possible risk mitigation strategies regarding weather.

\section{Rainfall analysis}

South Africa lies in the semi-arid subtropics where rainfall is strongly seasonal over much of the region, and is subject to marked internal fluctuations causing periods of drought or above-average rainfall. Various studies of rainfall also indicate that summer rainfall over large areas is influenced by the phase of the Southern Oscillation (see Nicholson \& Kim, 1997; Mason, 1995; Cook, 2000; Nicholson, 2003). The latest climatic classifications (see Figure 1 below) by Kruger (2004), published by the South Africa Weather Service, are in general agreement with the above. Rainfall stations used in this study are in regions 10 and 11 . 


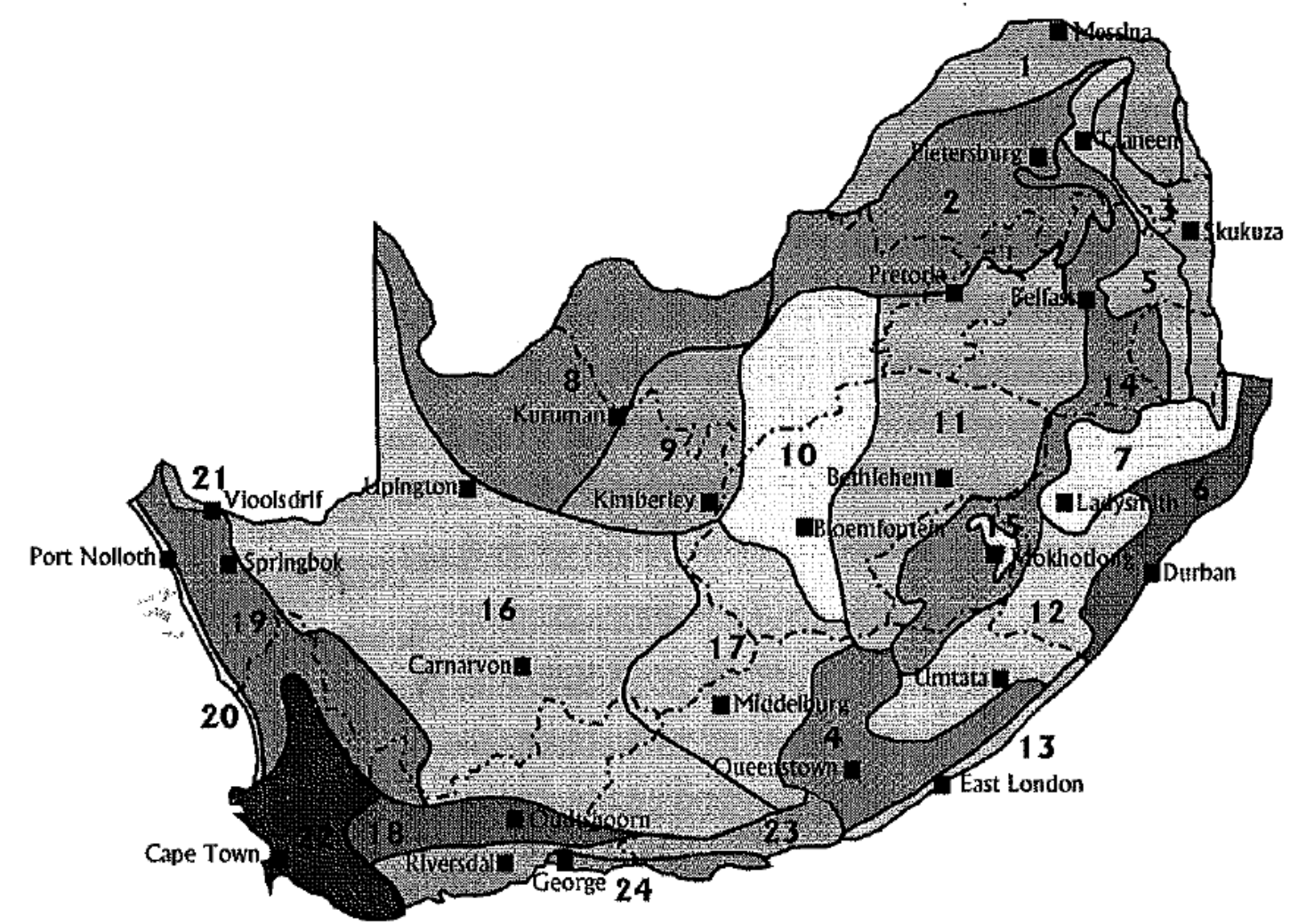

Figure 1: The climatic regions of South Africa

1. Northern Arid Bushveld. 2. Central Bushveld. 3. Lowveld Bushveld. 4. South-Eastern Thornveld. 5. Lowveld Mountain Bushveld. 6. Eastern Coastal Bushveld. 7. KwaZulu-Natal Central Bushveld. 8. Kalahari Bushveld. 9. Kalahari Hardveld Bushveld. 10. Dry Highveld Grassland. 11. Moist Highveld Grassland. 12. Eastern Grassland. 13. South-Eastern Coast Grassland. 14. Eastern Mountain Grassland. 15. Alpine Heathland. 16. Great and Upper Karoo. 17. Eastern Karoo. 18. Little Karoo. 19. Western Karoo. 20. West Coast. 21. North-Western Desert.

Source: Kruger (2004).

Temperature and rainfall are the two most important climatic factors imposing restrictions on human exploitation of soil through either under- or oversupply, or through fluctuations in time. In South Africa, temperatures are generally suitable for most agricultural activities during the summer rainfall season. On the other hand, rainfall is extremely variable from place to place, from day to day, from month to month, and from season to season, and it is the major factor imposing limits on agricultural development and water availability during the growing season.

\section{Rainfall distribution}

The purposes of this section are to statistically analyse and investigate rainfall distribution with reference to the interactions between rainfall and agriculture for the selected districts of Lichtenburg and Heidelberg, which are in different geographical and climatic rainfall regions of South Africa. The main aspects of rainfall commonly required by agriculturists, land-use planners and farmers 
concern the various rainfall characteristics such as quantity, spatial distribution, intensity, and variability. These make up the overall rainfall pattern. This information is also useful to financiers who would like to know what the risks associated with their investments are.

Rainfall variability is one of the most important factors determining variability in agricultural production. Economic pressure on farmers often exacerbates the downward spiral of land degradation via irreversible trade-offs between short-term economic gain and long-term sustainability. In this context, Basher (2000), Hammer (2000), Hansen (2002) and Podestá et al. (2002) show that an understanding of rainfall variability is essential for appropriate agricultural risk management, and Nelson et al. (2002) describe how an understanding of ENSO-related rainfall variability is becoming increasingly necessary in tactical risk-management approaches to agriculture.

The analyses were carried out in two phases - the descriptive and predictive. The descriptive analysis seeks to reveal year-to-year anomalies and variations in a number of rainfall characteristics based on historical data, for stations holding records for longer than 30 years, under the assumption that weather and rainfall patterns will continue to behave as in the past. The predictive phase is based on describing rainfall in terms of probabilities. Such probabilities can be used to the advantage of and in decision making on a variety of agricultural problems, for example, for the selection of appropriate dates for planting fields and drying hay, for solving problems of land use, and for water resources management.

Due to the complexity of the effect of rainfall on agricultural development, interpretation of the results obtained in both phases of rainfall analyses depend on the quality and quantity of available rainfall data and statistical methods used.

\subsection{Data and methods}

Rainfall, which is the amount of water falling as rain (and occasionally as hail or snow) over an area over a given period, is measured by collecting it in a container and expressing the depth per unit of surface water in millimetres, that has fallen within a specific period. In South Africa, rainfall is usually measured at 08:00 daily by lay observers, individuals and various institutions and organisations.

Rainfall data is sparse, and in some areas, long-term records are unavailable. The probability that some of the rainfall measurements are not made at 08:00 
or even on a daily basis, or that small amounts had been allowed to accumulate, gives reason for some uncertainties. Rainfall data could also include missing values which may influence probability studies. Another problem in South Africa is that rainfall is mostly of convective origin. Topography also has a major influence on rainfall patterns, especially over the high-ground and Drakensberg regions.

Bearing the above in mind, for the purposes of this study, seasonal decadal rainfall totals were calculated from September to April for six selected stations with more than 35 years of rainfall records. A decadal rainfall period can be defined as the 10-day periods between the $1^{\text {st }}$ and the $10^{\text {th }}$, and the $11^{\text {th }}$ and $20^{\text {th }}$ of each month, the last decade of the month having $8,9,10$ or 11 days (WMO 1966).

In view of some gaps in the continuity of the data, it was also necessary to fill in some missing values. First, decadal rainfall data values for nearby stations in the same rainfall region were calculated, correlated and compared with individual station's data. Missing data was then interpolated. Since the rainy season is from September to April, seasonal, monthly, and combined threemonthly rainfall totals covering the seasons were also calculated. The selected stations, their geographical coordinates, as well as first and last seasons' data available are shown in Table 1.

Table 1: Selected stations used in this study

\begin{tabular}{|l|c|c|c|c|}
\hline \multicolumn{1}{|c|}{ Station } & Longitude & Latitude & Season start & Season end \\
\hline Lichtenburg & 26.00 & -26.80 & $1960 / 61$ & $1999 / 2000$ \\
\hline Heidelberg & 28.37 & -26.50 & $1960 / 61$ & $1999 / 2000$ \\
\hline
\end{tabular}

\subsection{Statistical parameters}

Standard statistical parameters (average, standard deviation, and coefficient of variation $[\mathrm{CV}]$ ) were used in this study. Also, due to the fact that rainfall is not normally distributed, a simple method of calculating rainfall probability in the form of cumulative frequency distribution was used.

Probabilities of rainfall in the form of decile percentiles were calculated for each period by ranking rainfall from the smallest to the greatest amount. Decile values divide a set of observations into ten parts so that the nine deciles (D1, D2, up to D9) are such that $10 \%$ of data falls below D1, $10 \%$ falls between D1 and D2, 10\% falls above D9, and so forth. 
The median, or the $50 \%$ probability, or the $5^{\text {th }}$ decile, is the middle value of an ordered series of observations that divide the series into two halves: $50 \%$ above, and $50 \%$ below. In arid to semiarid regions, the arithmetic mean is not representative of the actual situation and can be misleading, and therefore, the median is preferred.

The coefficient of variation can be expressed as a function of the standard deviation to indicate the variability of rainfall. However, the use of the coefficient of variation has serious disadvantages, as rainfall data is generally skewed, especially when measured over short periods. A coefficient of variation exceeding 0.30 tends to indicate a substantial order of aridity with an unreliability factor that will render dry land cultivation exceedingly risky.

\section{Results and average climatology of South Africa}

\subsection{Average seasonal rainfall}

The agricultural significance of rainfall is closely related to its seasonal distribution, specifically where limited seasonal rainfall is reduced by high evaporative demands associated with semiarid climates. In general, the rainy season commences in September, with isolated falls over most of the country lasting until April. Agriculturally, October to December is taken as the early season (frequently the planting and growing season), and January to April as the late season (the ripening season). Figure 2 (Seasonal rainfall distribution) shows that rainfall decreases from east to west and that the eastern parts receive the most rainfall - just over $600 \mathrm{~mm}$ per annum. 


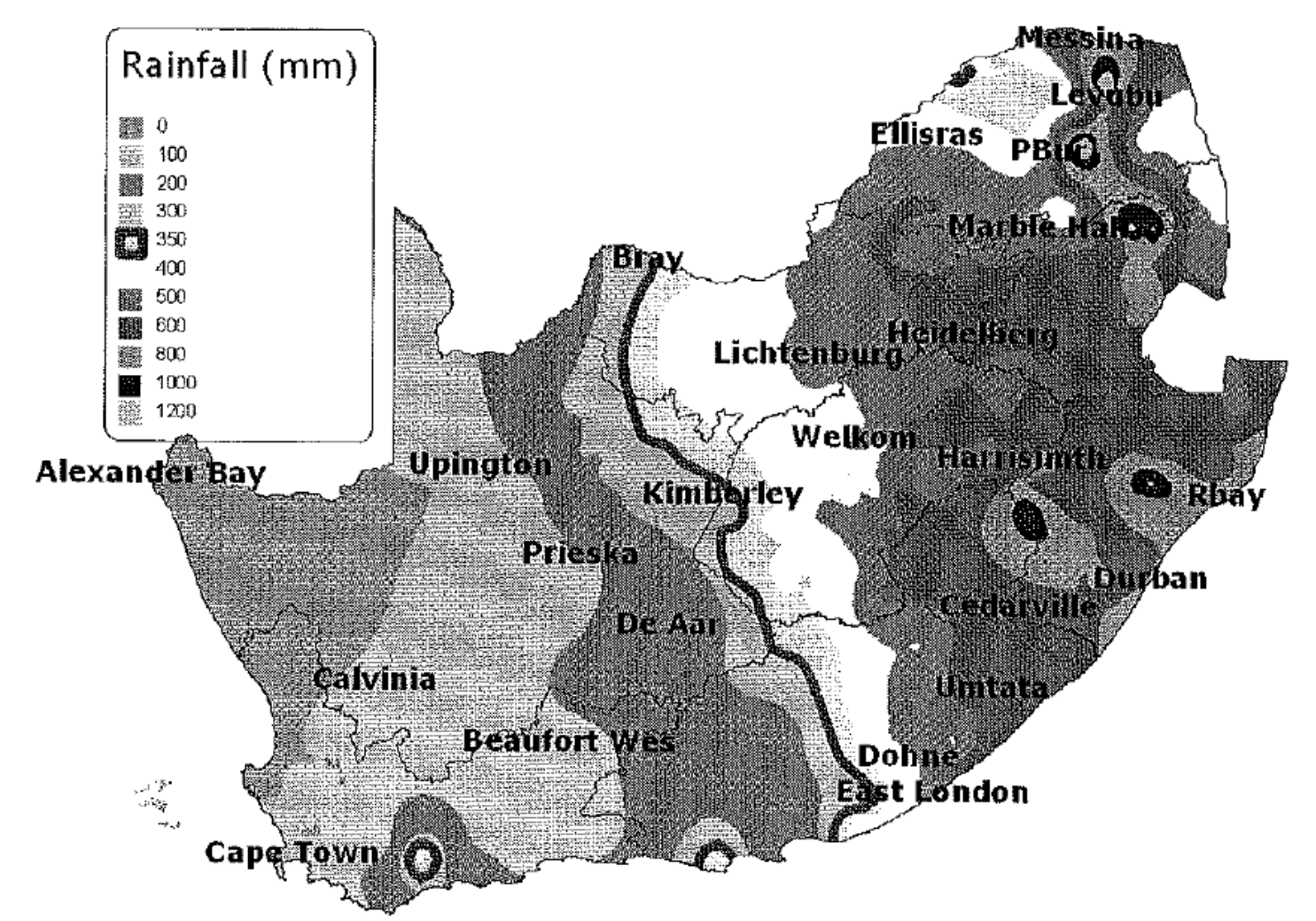

Figure 2: Mean seasonal rainfall $(\mathrm{mm})$ from April to September

Taljaard (1986) found that areas with the most rapidly increasing rainfall during monthly intervals are found to follow almost a circular path. Rainfall commences in September over the east coast of South Africa and is then successively displaced westwards over the central and western parts, ending in the Cape Provinces in March. December, January and February are the wettest months.

Since the availability of water is a major factor limiting production in dry-land farming, the uneven distribution of rainfall, together with only a single crop being grown during the season, creates an inherent risk for dry-land farmers. A potential geographical area where non-irrigated farming can be practiced is, therefore, of utmost importance to land-use planners and farmers in general. As $350 \mathrm{~mm}$ of rain is generally required for successful cultivation of dry land crops, the $350 \mathrm{~mm}$ isohyets are also shown. This implies that the area up to the red line in the above figure indicates the area where climatic conditions are suitable for the planting of maize.

The study of seasonal distribution and variability of rainfall will generally start with a monthly or 10-day period of rainfall. The seasonal distribution and variability of rainfall for the selected stations are best illustrated by the progression of rainy areas, based on the 10-day model, as is shown in Figures 3 and 4. 


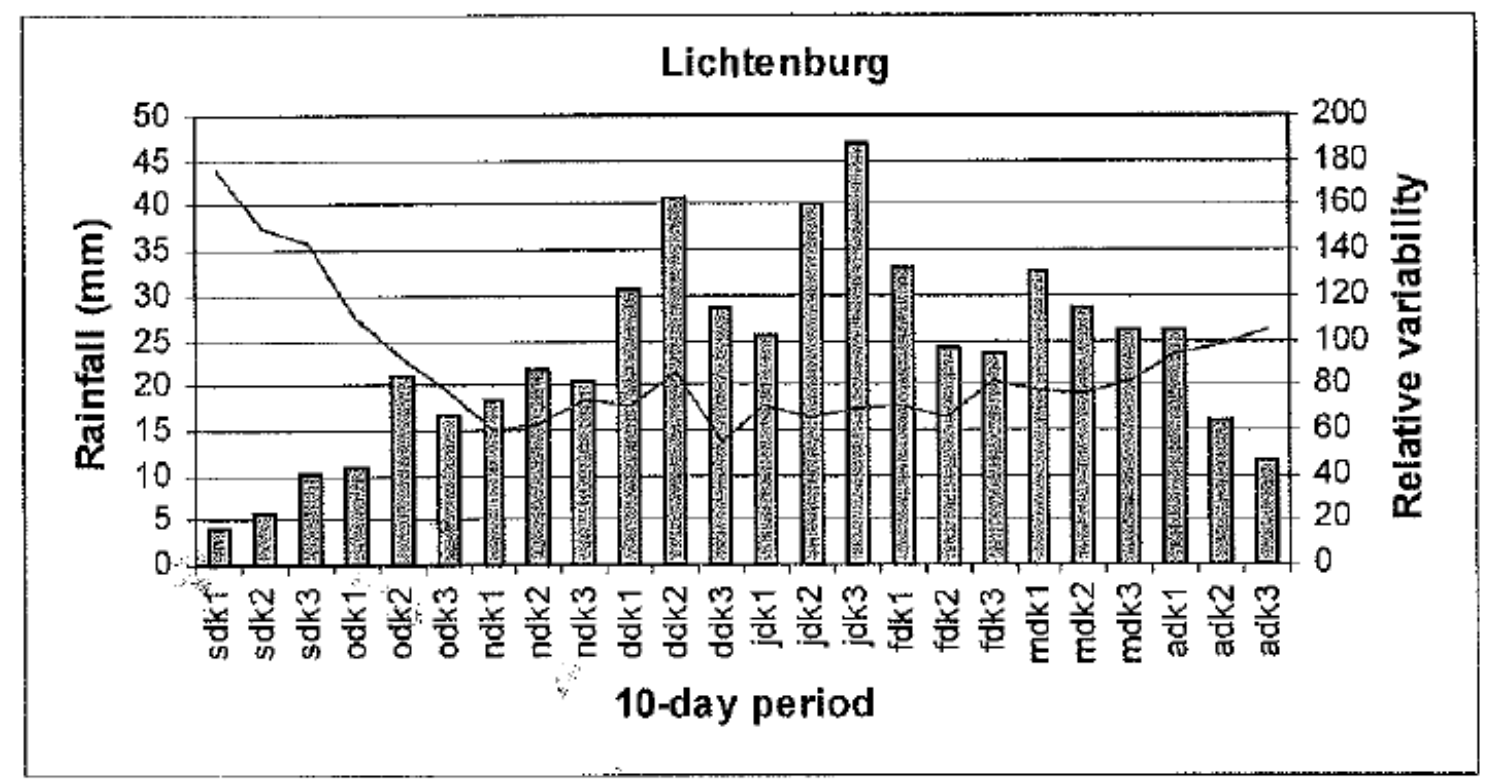

Figure 3: Ten-day rainfall and relative variability for Lichtenburg.

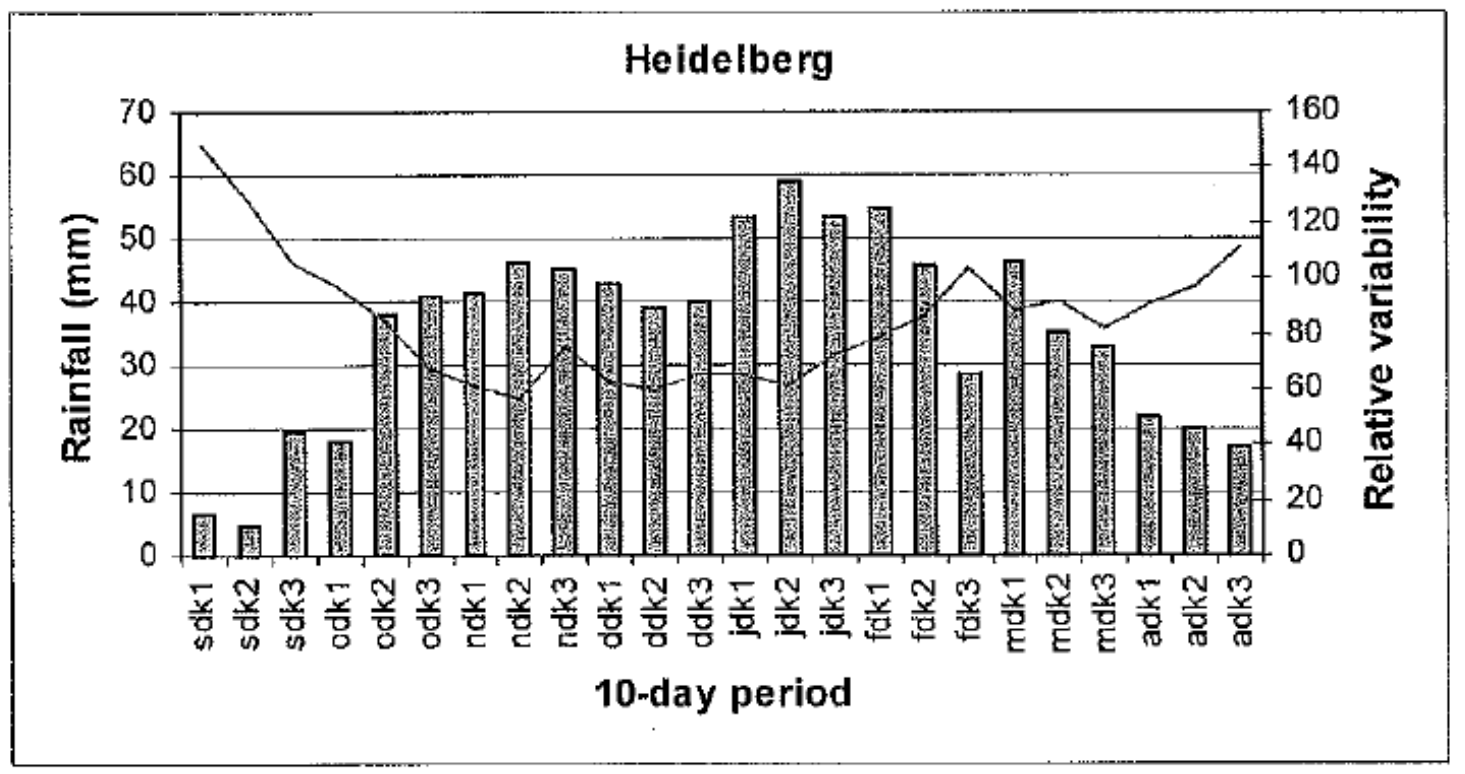

Figure 4: Ten-day rainfall and relative variability for Heidelberg.

From the above figures, it is evident that the lower the rainfall during a decade, the higher the variability. It also shows clearly that there is a correlation between variability and amount of rainfall. Therefore, rain received during drier decades (at the beginning and end of rainfall seasons) are more variable.

\subsection{Onset of the growing season - dry-land farming potential}

Farmers' cropping strategies are undoubtedly influenced by the variability in rainfall at the onset and at the end of the rainy season. As the first seasonal 
rains fall on soil which is generally dry on the surface and has a large soil moisture deficit, land preparation and the planting dates of crops depend entirely on the amount and frequency distribution of these early rains. It is therefore important for farmers to know when, on average, the beginning of the moisture growing season can be expected, when it ends, and how long the growing season is.

Kummerow and Giglio (1995) have developed a method of summing daily rainfall (or 10-day totals) forwards and backwards until a certain amount has been accumulated. Probabilities of having received given amounts of rain are then calculated. For this study, 10-day rainfall totals for the six stations were summed forwards and backwards (April to September) until a certain amount ( $25 \mathrm{~mm}, 75 \mathrm{~mm}, 200 \mathrm{~mm}, 350 \mathrm{~mm}, 400 \mathrm{~mm}$, or $500 \mathrm{~mm}$ ) had accumulated. The values of decades were then ranked in ascending order from the first date that a certain amount had been accumulated to the latest date. Probabilities were then calculated of having received varying amounts, and of certain amounts to be received during the growing period.

As maize is the most important dry-land crop grown and cultivated, the threshold for the onset of the rainy season was set at $75 \mathrm{~mm}$ of accumulated rainfall in a decade. The end of the growing season was terminated by the backwards summing of decadal data. The results obtained are shown in Table 2.

These results lead to the conclusion that one may expect that in 3 out of 4 years (a probability of $75 \%$ ) at least $75 \mathrm{~mm}$ will have accumulated by the first decade of November in Heidelberg, two decades later than in Lichtenburg (the third decade of November).

Similarly, there is a $75 \%$ probability that $350 \mathrm{~mm}$, the requirement for dry-land farming, can still be expected by the second and third decades over Heidelberg. Over Lichtenberg, $350 \mathrm{~mm}$ can still be expected by the first decade of November, indicating a higher risk for dry-land cultivation the further west one goes.

This presentation, based on rainfall totals, gives a good overall picture of the risk factor involved in agriculture in South Africa. However, the production of crops does not depend on rainfall alone, but also on the moisture status of the soils, i.e. the water balance interaction between rainfall and evapotranspiration. 
Table 2: Onset/end of rainy season based on forward/backward accumulation of 10-day rainfall totals

\begin{tabular}{|c|c|c|c|c|c|c|c|}
\hline \multicolumn{8}{|c|}{ Lichtenburg } \\
\hline Probability & $25 \%$ & $50 \%$ & $75 \%$ & Probability & $25 \%$ & $50 \%$ & $75 \%$ \\
\hline $25 \mathrm{~mm}$ & odk1 & odk2 & ndk1 & $500 \mathrm{~mm}$ & ddk1 & odk3 & sdk1 \\
\hline $75 \mathrm{~mm}$ & odk2 & ndk1 & ndk3 & $400 \mathrm{~mm}$ & jdk1 & ddk2 & odk2 \\
\hline $100 \mathrm{~mm}$ & ndk1 & ndk2 & ddk1 & $350 \mathrm{~mm}$ & jdk3 & ddk3 & ndk1 \\
\hline $200 \mathrm{~mm}$ & ddk2 & ddk3 & jdk2 & $200 \mathrm{~mm}$ & fdk3 & fdk1 & jdk2 \\
\hline $350 \mathrm{~mm}$ & jdk3 & fdk2 & mdk1 & $100 \mathrm{~mm}$ & mdk3 & mdk1 & fdk2 \\
\hline $400 \mathrm{~mm}$ & fdk1 & mdk1 & adk1 & $75 \mathrm{~mm}$ & adk1 & mdk3 & fdk3 \\
\hline $500 \mathrm{~mm}$ & $\mathrm{mdk} 1$ & adk3 & adk3 & $25 \mathrm{~mm}$ & adk2 & adk1 & $\mathrm{mdk} 3$ \\
\hline \multicolumn{8}{|c|}{ Heidelberg } \\
\hline Probability & $25 \%$ & $50 \%$ & $75 \%$ & Probability & $25 \%$ & $50 \%$ & $75 \%$ \\
\hline $25 \mathrm{~mm}$ & sdk3 & odk1 & odk2 & $500 \mathrm{~mm}$ & ddk3 & ndk2 & odk3 \\
\hline $75 \mathrm{~mm}$ & odk2 & odk3 & ndk1 & $400 \mathrm{~mm}$ & jdk2 & ddk2 & ndk3 \\
\hline $100 \mathrm{~mm}$ & odk2 & ndk1 & ndk2 & $350 \mathrm{~mm}$ & jdk3 & jdk1 & $\overline{d d k 1}$ \\
\hline $200 \mathrm{~mm}$ & ndk2 & ndk3 & ddk2 & $200 \mathrm{~mm}$ & fdk3 & fdk1 & jdk2 \\
\hline $350 \mathrm{~mm}$ & ddk3 & jdk2 & fdk1 & $100 \mathrm{~mm}$ & mdk3 & mdk1 & fdk3 \\
\hline $400 \mathrm{~mm}$ & jdk1 & jdk3 & fdk2 & $75 \mathrm{~mm}$ & mdk3 & mdk2 & fdk3 \\
\hline $500 \mathrm{~mm}$ & jdk3 & fdk1 & mdk3 & $25 \mathrm{~mm}$ & adk2 & adk2 & mdk3 \\
\hline
\end{tabular}

\section{Crop production and monitoring}

Maize is the most important crop grown in South Africa and has shown some striking progress in increased yields as a result of the evolution of new drought-resistance cultivars and farming techniques. As a result of the evolution of new techniques and cultivars, the living conditions of large numbers of farm workers improved, causing a migration from rural areas to cities and leading to a greater consumption of other products such as wheat.

The aim of this section is to analyse the yields 4 obtained in the two regions over a period of 26 years and to determine whether strong correlations exist between the yields obtained in the various areas. Figure 5 shows the yield production for the selected stations for the seasonal period 1980/81 to 2003/04.

\footnotetext{
${ }^{4}$ Appreciation is accorded to the National Department of Agriculture for providing the selected data.
} 


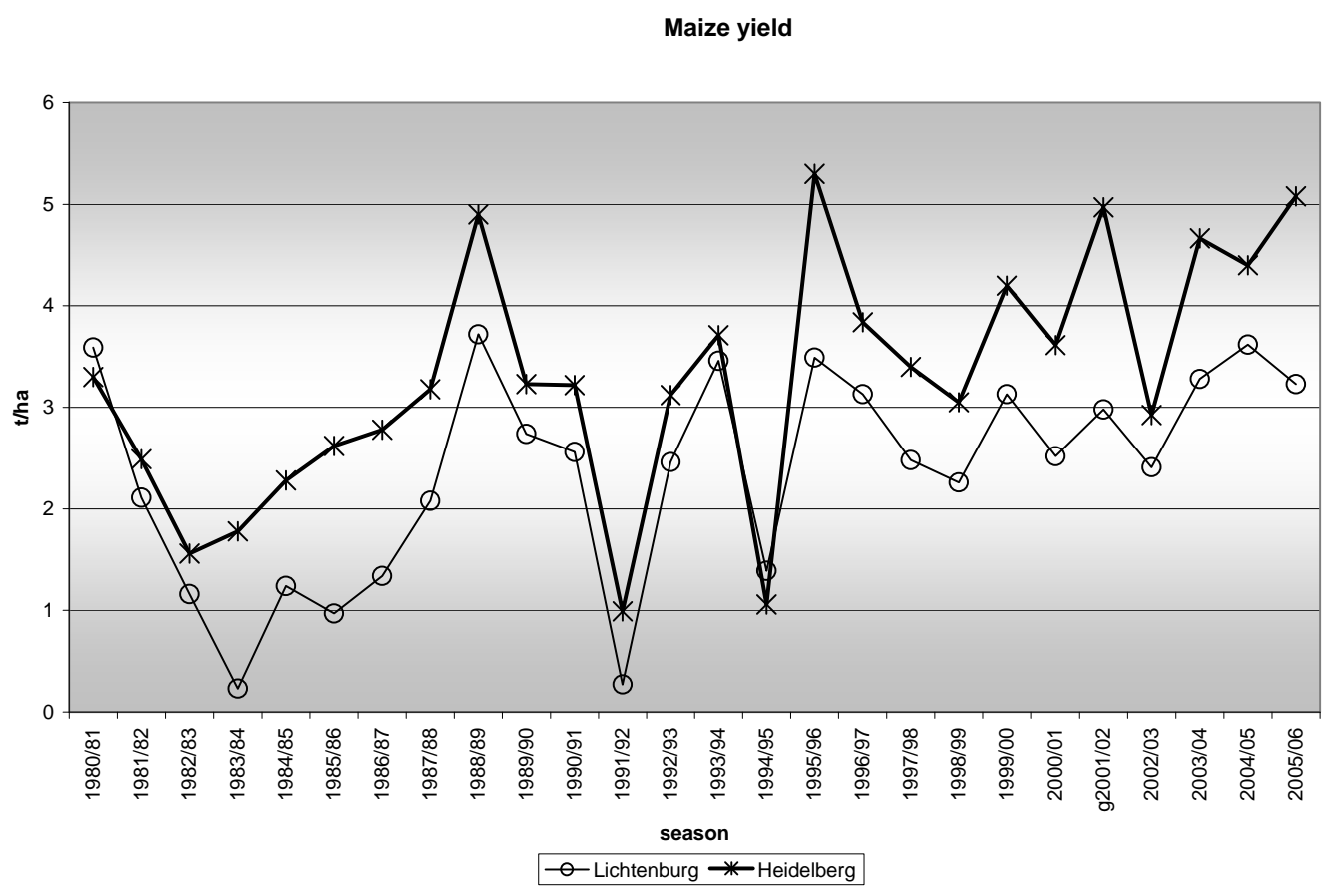

Figure 5: Maize yields for selected stations

Table 3 indicates the average yields obtained during the period of investigation.

Table 3: $\quad$ Average maize yields obtained in the selected areas

\begin{tabular}{|l|r|r|r|}
\hline & 1980/81-2005/06 & 1980/81-1998/99 & 1999/00-2005/06 \\
\hline Heidelberg & 3.3 & 2.9 & 4.3 \\
\hline Lichtenburg & 2.4 & 2.1 & 3.0 \\
\hline
\end{tabular}

A considerable difference between the yields of the different periods exists. The next step was to determine the correlation between the various areas based on yield. Table 4 indicates the correlation for the period 1980/81 to 2005/06, showing the relationship between climate variability such as drought or extreme wet conditions at the same time affecting yield.

Table 4: Yield correlations from 1980/81 to 2005/06

\begin{tabular}{|l|r|r|}
\hline & Lichtenburg & \multicolumn{1}{|c|}{ Heidelberg } \\
\hline Lichtenburg & 1 & 0.862923 \\
\hline Heidelberg & 0.862923 & 1 \\
\hline
\end{tabular}

There exists a strong positive correlation between the geographically dispersed areas. Based on the above table, it is clear that diversification based on yields between the areas is of limited benefit. The next step was to break 
the total data period into two groups, i.e. data for the period prior to 1999/00 and data for the period after 1999/2000. Tables 5 and 6 show the results.

\section{Table 5: Yield correlations from 1980/81 to 1998/99}

\begin{tabular}{|l|r|r|}
\hline & Lichtenburg & Heidelberg \\
\hline Lichtenburg & 1 & 0.858377 \\
\hline Heidelberg & 0.858377 & 1 \\
\hline
\end{tabular}

There is again a strong positive correlation between the two stations. For this period, the same argument, based on geographical diversification, is true. Table 6 analyses the areas based on the last seven years.

\section{Table 6: Yield correlation for the period 1999/2000 to 2005/06}

\begin{tabular}{|l|r|r|}
\hline \multicolumn{1}{|c|}{} & Lichtenburg & Heidelberg \\
\hline Lichtenburg & 1 & 0.736754 \\
\hline Heidelberg & 0.736754 & 1 \\
\hline
\end{tabular}

Interesting to note is that during this period the correlation between the two areas diminishes, although they are still strongly and positively correlated. However, possible climate change and frequent droughts over the same area during the past years are of serious concern to the government, land-use planners, financiers, and farmers. This concern is not only because climate change or drought may reduce all crop and livestock yields, but because of the related effects these have on the majority of people and the economy of a country.

Therefore, the monitoring of the growing season and the growth of cultivars (maize and wheat) is an important process in risk management and food security. A forecast of possible yield size in advance becomes a necessity.

\section{Conclusions and recommendations}

Rainfall is and always will be the main climatic element affecting agricultural and economic development in South Africa. The high frequency of drought, possible climate change, plus the present increase and migration of large masses of people can have catastrophic economic and social implications. To safeguard against future famines and possible food and water shortages, it is necessary that more research be done on the effects of climatic variations on water and food security. 
This study consisted of two parts. The first involved the reconstruction of missing decadal data for six selected stations, and the second statistically analysed the 10-day data for the selected stations in order to present general aspects, probabilities, rainfall tendencies, and possible projections.

From a study of the maps and statistical analyses of selected stations, it is clear that rainfall distribution varies greatly from east to west to southwest, which makes dry-land farming, especially in the western parts, extremely risky.

By employing the method of forward and backward summing of 10-day rainfall for selected stations at the onset of the growing season when at least 75 $\mathrm{mm}$ can be expected, is from the first decade of November and the cut-off date is by the first decade of March.

Temperatures are suitable for most crops grown, but a possible increase in temperature due to climate change will increase evaporation and needs to be investigated.

From this study, it is clear that more research in crop monitoring using the water model for estimating regional crop production is needed. Risk can be quantified better with a potential evapotranspiration (PET)model if specific planting dates are available. It is clear from the study that the selected regions have limited risk diversification based on geographic dispersion. It is also clear that the uninsured part of the production season can be better managed with planned planting dates based on a required minimum rainfall and probabilities of sufficient follow-up rainfall during the following decadal. More in-depth research might provide insurers with a product focusing only on the un-insured part of the growing season. Based on the average yields obtained during the period 1999/2000 to 2005/05, limited risk of a total crop failure exists. With good price-risk management strategies, financial institutions could most likely obtain a price sufficient to cover their costs, even if insurers had to pay out due to a failed crop.

\section{References}

Basher R (2000). The goals of the forum. Proceedings of the International Forum on Climate Prediction, Agriculture and Development, IRI-CW/00/1, pp. 1-2. International Research Institute for Climate Prediction, Colombia University.

Cook KH (2000). The South Indian convergence zone and interannual rainfall variability over southern Africa. Journal of Climatology 13:3789-3804. 
Hammer GL (2000). A general systems approach to applying seasonal climate forecasting. In Hammer GL, Nicholson N \& Mitchell C (eds). Applications of seasonal climate forecasting in agricultural and natural ecosystems - the Australian experience. Dordrecht: Kluwer Academic. 51-65.

Hansen J (2002). Realising the potential benefits of climate prediction to agriculture: issues, approaches, challenges. Agric Systems 74:309-330.

Kruger AC (2004). Climate of South Africa: climate regions. WS45. Pretoria: South African Weather Service.

Kummerow C \& Giglio L (1995). A method for combining passive microwave and infrared rainfall observations. Journal of Atmospheric and Oceanic Technology $12: 1,33-45$.

Mason SJ (1995). Sea surface temperature: South African rainfall associations, 1910-1989. International Journal of Climatology 15:119-135.

Nelson RA, Holzworth DP, Hammer GL \& Hayman PT (2002). Infusing the use of seasonal climate forecasting into crop management practice in North East Australia using discussion support software. Agric Systems 74, 393-414.

Nicholson SE (2003). Comments on the South Indian Convergence Zone and interannual rainfall variability over Southern Africa and the question of ENSO's influence on Southern Africa. Journal of Climatology 16:555-562.

Nicholson SE \& Kim J (1997). The relationship of the El Nino-Southern Oscillation to African rainfall. International Journal of Climatology 17:117-135.

Podestá G, Letson D, Messina C \& Royce F (2002). Use of ENSO-related climate information in agricultural decision making in Argentina: a pilot experience. Agric Systems 74, 371-392.

Taljaard JJ (1986). Change of rainfall distribution and circulation patterns over Southern Africa in summer. Journal of Climatology, 6:579-592.

WMO (1966). International Meteorological Vocabulary. WMO No. 182, TP 91. Geneva: World Meteorological Organisation. 